\title{
La ciudadanía múltiple: revisiones y nuevas perspectivas
}

\author{
Guillermo de la Peña
}

MARCO A. CALDERÓN MOLGORA, WILLEM ASSIES

Y TON SALMAN (eds.), 2002

Ciudadanía, cultura política y reforma del Estado en América Latina

248 El Colegio de Michoacán-Instituto Federal Electoral (Michoacán),

Zamora y Morelia, México, 534 pp.

\begin{abstract}
$\mathrm{A}^{\mathrm{n}}$ través de un conjunto de 22 capítulos, los autores de este ambicioso libro se proponen replantear y al mismo tiempo recuperar el concepto de ciudadanía en el estudio de los procesos políticos de la América Latina contemporánea. Replantear, puesto que la versión liberal de tal concepto e incluso la formulación ampliada de Marshall parecerían superadas en el contexto del surgimiento de nuevos sujetos sociales, de la creciente heterogeneidad y "desterritorialización" de
\end{abstract}

sus demandas, y de la puesta en tela de juicio del Estado-nación en cuanto matriz hegemónica de los derechos ciudadanos. Recuperar, porque la noción de ciudadanía sigue siendo necesaria para la comprensión de las luchas democráticas del cambio de siglo (que los propios participantes con frecuencia definen como luchas ciudadanas), así como de los debates en torno a las relaciones entre la sociedad civil, el mercado y la política. En tal recuperación, los autores pretenden

GUILleRmo DE LA PEÑA: CIESAS-Occidente.

Desacatos, núm. 15-16, otoño-invierno 2004, pp. 248-251.

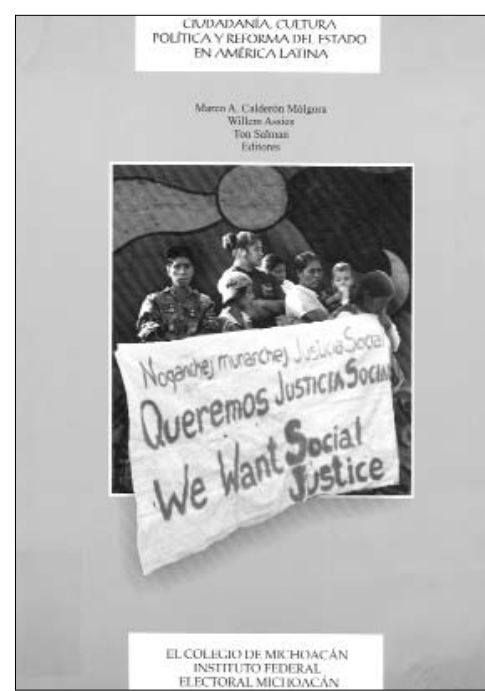

complementar el enfoque formal o macrosociológico - predominante en los estudios sobre el tema- con un enfoque antropológico (etnográfico) que muestre la importancia de la cultura y la vida cotidiana en el análisis de las prácticas ciudadanas y de sus condiciones de posibilidad. Este interés en el mundo de la cultura, las identidades y las formas de sociabilidad como constitutivo de los procesos de cambio político es uno de los 
grandes méritos del volumen: permite, en el contexto latinoamericano de transición a la democracia liberal y a la globalización capitalista, entender la construcción de la ciudadanía, en términos de las búsquedas conflictivas, por actores sociales múltiples, de modalidades nuevas y más genuinas de reconocimiento e inclusión, equidad y representación.

Después de una primera sección ("Ciudadanía en entredicho") que recoge una introducción de los compiladores — bien informada y lúcida en su discusión de los temas y problemas pertinentes- el volumen incluye otras seis secciones. En la segunda ("Formación de ciudadanías") hay sendos capítulos sobre la historia reciente de Bolivia, Perú y México, y otros dos más generales sobre las últimas décadas de América Latina. El estudio de Bolivia, escrito por Rossana Barragán, da cuenta de la continuidad, desde el siglo XIX, de las expresiones legales de las jerarquías y exclusiones (sobre todo en materia de género); el trabajo de Fiona Wilson sobre el Perú decimonónico se refiere al manejo de los espacios públicos en la ciudad de Tarma como expresión de la exclusión étnica; y el de Marco A. Calderón analiza, para el caso de Michoacán, las políticas agrarias, educativas e indigenistas en la década de 1930. Estas políticas, según muestra Calderón, condicionaban drásticamente el reconocimiento del mundo indígena a la transformación de las comunidades en términos de la modernidad decretada por el Estado populista. Por su parte, el capítulo de Ton Salman muestra los factores internacionales e

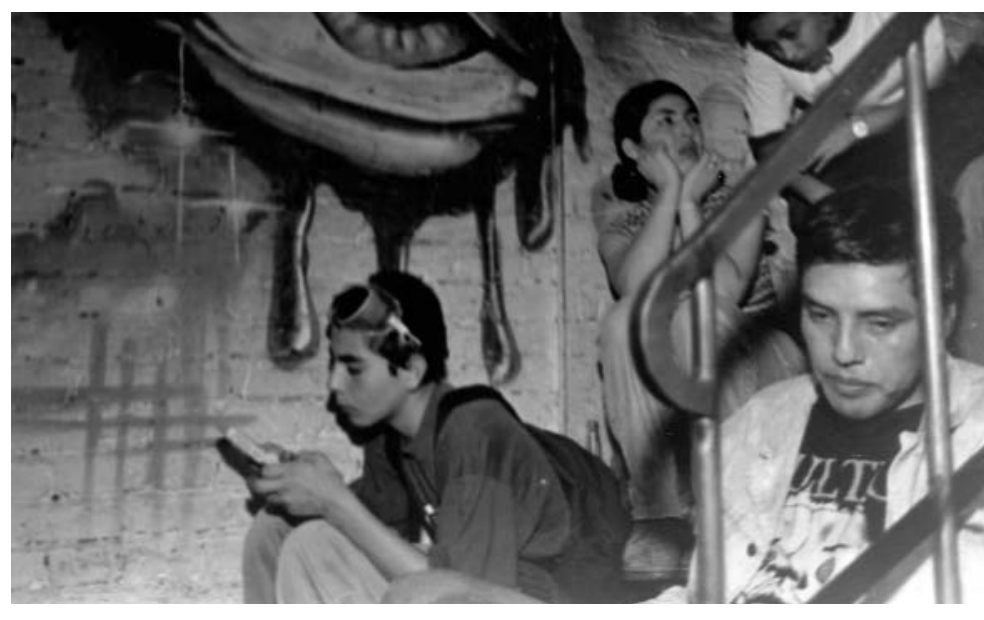

Multiforo Alicia / Foto: Arturo Fuentes.

intranacionales que vuelven problemático el carácter de la ciudadanía en nuestro subcontinente, y apela a la necesidad de estudios etnográficos comparativos que muestren "desde abajo" la pluralidad de escenarios donde ciertas demandas se vuelven efectivas; el de Willem Assies busca discutir la relación entre los conceptos de ciudadanía y sociedad civil y calibrar sus posibilidades de análisis para América Latina, sobre todo en relación a los movimientos sociales, que han entendido la ciudadanía como un proceso de ampliación de derechos tanto individuales como colectivos y se han negado a divorciar la acción civil de la política.

La tercera sección ("Ciudadanía, ajustes y reformas") se centra en los impactos de las reformas estatales y los ajustes estructurales. La abre un capítulo de Jorge Máttar sobre los cambios macroeconómicos en la región latinoamericana —donde sobresalen las políticas de privatización y liberalización comercial, destinadas a recuperar el equilibrio y lograr mayores tasas de inversión-, al que sigue un estudio de Lúcio Kowarick sobre la vulnerabilidad extrema de los pobres urbanos en Brasil. Kowarick afirma que la democracia política de corte liberal es totalmente incapaz no sólo de combatir tal vulnerabilidad sino también de garantizar los derechos civiles y sociales de la población en general, habida cuenta de los procesos de exclusión inherentes a la estructuración económica. La propia idea de exclusión (e incluso "des-ciudadanización") informa el análisis que hace Tom Kruse del debilitamiento sindical boliviano, que fue factor y consecuencia de los ajustes estructurales en la economía y la organización laboral. Igualmente, el capítulo de Emilio Duhau, que reseña (sobre todo para México) el paso del modelo corporativo de servicios sociales, selectivo en sus beneficios, a un modelo descentralizado, formalmente abierto y compensatorio, no es precisamente optimista: muestra, por ejemplo, la reedición disfrazada de prácticas clientelares y excluyentes. 


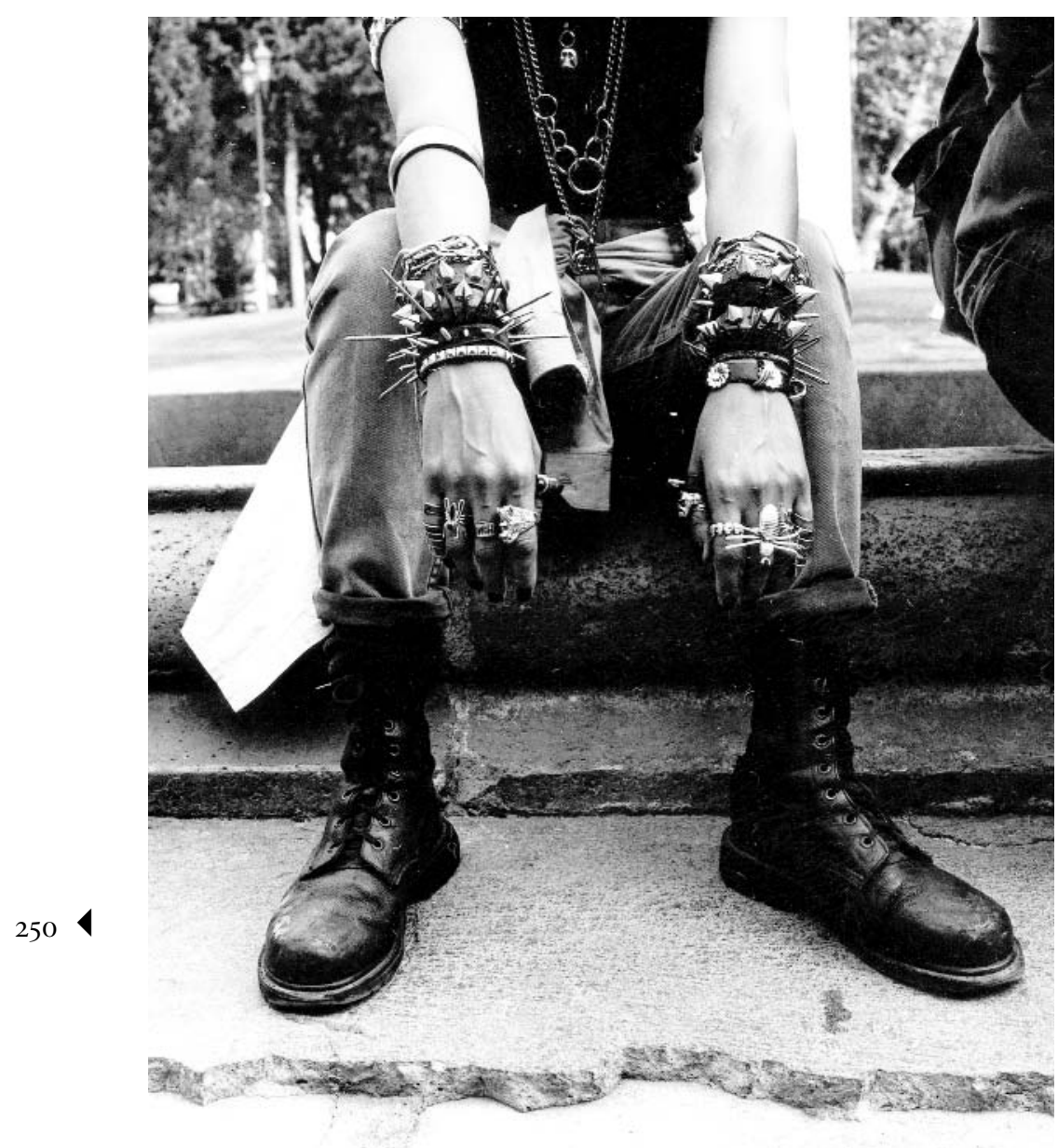

Foto: Arturo Fuentes.

La cuarta sección ("Democracias y culturas políticas") vuelve la mirada a las actitudes y estrategias de los sujetos sociales frente a la realidad de los Estados que no terminan de desmantelar el autoritarismo y parecen ahondar con sus políticas el problema de la exclusión. El ensayo de Wil Pansters revisa críticamente dos modelos de investigación sobre cultura política —el derivado de la ciencia política estadounidense, que tiende a reificar "los valores", y el de los historiadores de las ideas, que postulan la continuidad secular de una matriz "personalista" y autoritaria- para proponer como alternativa un modelo centrado en la exploración cualitativa de las prácticas político-culturales. Laura Tedesco, refiriéndose a los casos de Argentina y Brasil, examina tres "dimensiones teóricas" (idea, contrato social, institución) del Estado "posautoritario" (en una línea que se deriva de los análisis de O’Donnell y busca trascenderlos), para mostrar la inca- pacidad de consolidar la democracia en sociedades "neoliberales" donde persisten las desigualdades profundas y la represión. Para México, Jacqueline Peschard muestra que, con todo y lo valioso —e indispensable - de las nuevas reformas y prácticas electorales, éstas no bastan para lograr la democratización del país: es menester crear formas amplias de participación, reconocimiento de la pluralidad cultural e identitaria y un "patriotismo democrático" —en la fórmula habermasiana—comprometido con el respeto irrestricto a los derechos humanos. Y Lucy Taylor ejemplifica con el caso argentino dos tipos de cultura política que centran la atención en las relaciones entre el partido y el ciudadano: el que se basa en relaciones patrón-cliente y el que privilegia el seguimiento de una vanguardia de líderes o personajes "que saben lo que hay que hacer": ambos modelos no democráticos entran en crisis (por el "desencanto ciudadano") al advenir la ideología neoliberal, pero las sociedades que los sufrían aún no encuentran una alternativa democrática.

La quinta sección ("Refundar o refundir: la ciudadanía étnica") retorna a una cuestión planteada ya en el capítulo de Peschard: cuál debe ser la conceptualización de la ciudadanía en un contexto de culturas múltiples e identidades plurales. Bartolomé Clavero mira las elecciones peruanas de 2001 en términos de la relación de "inconstituyencia" (sic) entre el Estado y los sujetos políticos indígenas (esto es: la brecha entre la condición de elector y la condición de ciudadano, creada en buena medida por disposi- 
ciones administrativas). La difícil cuestión de los derechos ciudadanos diferenciados en una democracia moderna que busca la igualdad en el acceso a bienes estratégicos es abordada por Leticia Santín, al examinar los casos de los estados de Chiapas y Oaxaca, en México: mientras que el segundo estado dio pasos significativos en la reforma municipal para dar cabida al reconocimiento de la diversidad étnica, en Chiapas, la ausencia de reformas semejantes a nivel local -fundamental para el cambio democrático- ha generado conflictos persistentes. Eduardo Zárate usa el término "comunalismo modernizante" para examinar los movimientos indígenas de los últimos 20 años, que a partir de la reivindicación comunitaria redefinen y "legitiman la participación de este sujeto colectivo en espacios antes prohibidos". A pesar de que muchos de estos movimientos no fueron inmunes al caudillismo y la cooptación, otros se han insertado exitosamente en el proceso de democratización y apertura global de la sociedad mexicana. A su vez, Rosalba Aída Hernández Castillo re-visita las comunidades chiapanecas estudiadas por ella desde hace una década para encontrar los cambios en la conciencia de los derechos y las nuevas luchas contra la exclusión y la opresión, no sólo en términos de la diversidad étnica sino asimismo en términos de reivindicaciones de género en el interior de las propias comunidades indígenas.

"Globalismos y localismos" es el título de la sexta sección. Martín Hopenhayn habla de la "ciudadanía descentrada" en una sociedad global organizada de manera análoga a las redes informáticas, donde "mientras aumentan las posibilidades de ejercer [la ciudadanía]... en un imaginario global marcado por la democracia política, los derechos humanos y el derecho a la diferencia, por otro lado el modelo económico vigente tiende a generar retrocesos en los derechos económicos y sociales para gran parte de la población latinoamericana”. Benjamín Arditi se refiere a la "migración" de la política "hacia el espacio supuestamente neutral de la sociedad civil y actualmente hacia ámbitos fuera del territorio del Estado-nación”, y a la proliferación de ámbitos supranacionales de representación ciudadana. Y Patricia Safa diserta sobre la construcción de "lo popular" y "lo local" en el contexto de la globalización.

Finalmente, la séptima sección ("Conclusiones") recoge un capítulo de John Gledhill que intenta — con éxito- recoger los debates, cuestionamientos y "desconstrucciones" presentes en el volumen, así como destacar la mezcla de conclusiones optimistas, realistas y pesimistas. Cuestiona la visión del "avance de la ciudadanía” desde el modelo europeo y muestra, con base en varios capítulos del libro, los aspectos que más bien deben entenderse como retrocesos; $y$ propone, al igual que muchos de los autores, que los avances remiten sobre todo a los esfuerzos de construcción de la ciudadanía "desde abajo". Aborda también la cuestión del nacionalismo y de la imagen neoliberal del "Estado flaco", que en realidad no lo es tanto en lo que se refiere a la promoción y defensa coercitiva de un modelo eco- nómico antipopular, así como la paradoja de la posmodernidad, que se quiere definir por redes "descentradas" que en realidad ahondan las relaciones hegemónicas. Y de nuevo contrasta dos enfoques: el que ve las alternativas futuras de organización de una ciudadanía más equitativa e incluyente en la acción de un Estado tutelar vinculado a organismos internacionales igualmente tutelares, con el que postula la importancia del fortalecimiento de las organizaciones locales en la promoción y viabilidad de esa misma ciudadanía.

Este libro se originó en el Coloquio Anual de El Colegio de Michoacán en 2001, y ya es costumbre, por más de 20 años, que estos actos académicos logren reunir en la ciudad de Zamora a investigadores de primera línea, tanto nacionales como internacionales. Las secciones logran recoger los grandes temas que atraviesan la discusión de la ciudadanía, analizados desde distintas perspectivas, y sitúan tal discusión en un ámbito específicamente latinoamericano. Los capítulos incluyen disquisiciones conceptuales, estudios basados en fuentes secundarias, estudios que se apoyan en trabajo de archivo, y etnografías. Hubiera sido deseable contar con más capítulos etnográficos, dada una de las insistencias del libro. De cualquier forma, podemos vaticinar que se convertirá en una referencia obligada para quienes se interesan por el estado del arte en los debates académicos sobre la ciudadanía y también para los activistas de la sociedad civil y los militantes políticos que busquen una base reflexiva sólida. 